\title{
Automatic On Load Voltage Regulating Technology and Energy-saving HID Lamps
}

\author{
Jinlong $\mathrm{Tu}^{1, \text { a }}$, Yanxia $\mathrm{Li}^{2, \mathrm{~b}}$ \\ 1,2 Nanjing Communications Institute of Technology,Nanjing,China \\ atjl@njci.cn, ${ }^{\mathrm{b}}$ jddq2016@163.com
}

\begin{abstract}
Keywords: Circuit; HID; OLTC; Simulation; Transformer; Triac; Waveform
\end{abstract}
Abstract. This report analyses the current typical non-contact On-Load Tap Changer(OLTC) thyristor products, poses the circumfluent calculating formula, and points out the main problems existed. The paper also introduces the highly-performed and highly-reliable thyristor OLTC technology and products. Compared with the current technology, high power thyristors will be decreased to half in amount, the high power current limiting resistances or reactors will no longer be used. The current can be continuous without impact, over-voltage or voltage drop phenomena when changing the transformer taps. This kind of technology will have positive significance on High-Intensity Discharge(HID) lamps energy saving, lamps service life extending and non-contact OLTC performance improving of the intelligent power grid.

\section{Introduction}

Power electronic technologies have extremely important effect on electric energy saving. High intensity discharge lamps (HIDs) belong to those energy-efficient lamps, including high pressure sodium lamps, high pressure mercury lamps and metal halide lamps. For HID lamps, appropriate voltage reduction will not only save energy efficiently, but also can lengthen lamps' service life. This automatic voltage regulator can be adjusted to meet the voltage applied to the lamp at different times during the day and extreme weather the demand for different road illumination ${ }^{[1]}$. Related experimental research report has pointed out that when the voltage of the lamp surpasses by $10 \%$, a lamp's life span decreases to half; when the voltage of the lamp remains to be $90 \%$ of the rated one, a lamp's life span will be double.

On-load voltage regulating transformer on load adaptive regulation is the common used method of voltage control in power grid, People have published many papers and monographs about some studies suggest that the OLTC transformer is considered to be one of the important factors causing voltage collapse $^{[2-10]}$. Especially in the inductive load, the thyristor element prone to malfunction cause the regulator to fail, seriously affected the reliability of the transformer load tap ${ }^{[11]}$.

For HID lamps, current discontinuity with Millisecond level is likely to cause unstable voltaic arc, what will lead to lights out or lamps' life span decreasing. As a result, OLTC devices with mechanical contacts or non-contact current limiting resistances are not fit for HID lamps. With using these kinds of products, the lamps are easy to be lighted out and broken down. The reason is that the voltage causes the HID lamps' discontinuous current when the transformer taps are changed, and even impact current, as well as instant over-voltage and voltage dropping can be caused probably, what is easy to cause HID lamps lighting out or re-lighting. It will accelerates HID lamps' aging and decreases the lamps' life span, the new problems such as energy saving but money wasted will be brought at the same time.

In conclusion, it is significant to research on highly-performed, highly-reliable and rapid OLTC devices which will be able to avoid current discontinuity, current impact and over-voltage when changing the transformer taps ${ }^{[12]}$. 


\section{Current Typical OLTC Thyristor Product Analysis}

Non-contact OLTC technology has an easy principle, but if the core techniques do not reach the standard, transition resistance or transited inductance components must be united in series in the thyristor loop, to limit the current impact occurred in taps change, which is hard to consider high performance and high reliability.

This kind of products not only occupies many high-power components and high cost, but also leads to poor property as well as impact current and output-voltage dropping while changing the transformer taps. Current products are almost in this mode, and the analysis comes as following.

\section{A. The Main Electric Loop of the OLTC}

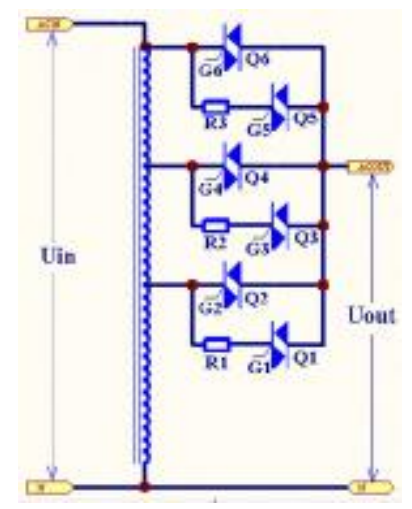

Fig. 1. The schematic diagram of the Main electrical Loop of current typical OLTC thyristor

Fig. 1 is the schematic diagram of the Main electrical Loop of current typical OLTC thyristor ${ }^{[12]}$, there are 3 taps which can be adjusted, the 3 sets of non-contact switches are used on Fig. 1, every set of non-contact switch are comprised of 2 high-power and two-ways thyristors and 1 high-power resistance which is the transition resistance like $\mathrm{R} 1, \mathrm{R} 2, \mathrm{R} 3$.

\section{B. Controlling Method of Taps Change}

Take an example of the changing process from Q1, Q2 to Q3, Q4, the details as following:

1) The original state is that $\mathrm{Q} 1$ and $\mathrm{Q} 2$ gates on, the load wades the resistance to get electricity from the bottom of the triac through Q2. It starts to change.

2) Trigger Q3, and stop triggering Q2, so that Q3 and the resistance R2 go through the circulation formed by the on-load current and Q2 form a circulation . After half circle, the natural current of Q2 shuts at zero. Q1/Q3 carries the on-load current together and the circulation decreases half. After stopping tripping Q2 for 15 milliseconds, trip Q4, and leave Q1 to natural shut after stopping tripping. The whole changing process ends and Q4 provides the whole on-load current.

\section{The Simplified Equivalent Circuit}

The simplified equivalent circuit of the OLTC thyristors is showed as Fig. 2, $\Delta \mathrm{U}=\mathrm{k}_{1} \mathrm{U}_{\mathrm{i}}, 0<\mathrm{k}_{1}<1$.

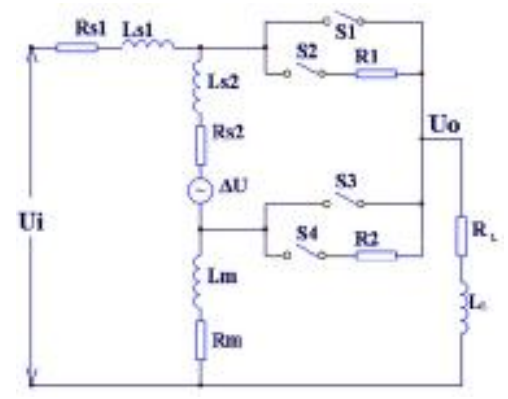

Fig. 2. The simplified equivalent circuit of the OLTC thyristors 


\section{The Formation of OLTC}

The transformer usually works closely to the saturation segment of the magnetization curve, with the nonlinear characteristics of its dynamic regulating properties, which makes it hard to do quantitative analysis during work process.

Suppose the voltage of transformer's voltage regulating winding is $\Delta \mathrm{u}=\Delta \mathrm{Um \operatorname {sin }}(\omega \mathrm{t}+\theta)$, ih as the circular current caused by $\Delta \mathrm{u}$ in the loop of RS2,LS2,S2,R1,S3 and $\Delta \mathrm{U}$ during the switching process of S2 and S3 being closed, set the loop equation as following ${ }^{[13]}$ :

$$
\left(R_{1}+R_{S 2}\right) i_{h}+L_{S 2} \frac{d i_{h}}{d t}=\Delta U_{m} \sin (\omega t+\theta)
$$

Solve it, get :

$$
i_{h}=\mathrm{I}_{h m} \sin (\omega t+\theta-\alpha)+A e^{-\frac{R}{L_{S 2}} t}
$$

In which

$$
\begin{aligned}
& R=R_{1}+R_{S 2} \\
& \alpha=\arctan \left(\omega L_{S 2} / R\right) \\
& I_{h m}=\frac{\Delta U_{m}}{\sqrt{\left(\omega L_{S 2}\right)^{2}+R^{2}}}
\end{aligned}
$$

\section{E. Analysis}

Usually, the number of windings is small, so RS2 and LS2 have few functions. Circular current is bound to exist among the transformer's secondary windings. According to the transformer's principle, it will definitely run through the primary windings and form impact current in the net's side. This impact current will inevitably lead to an abnormal drop of output voltage. If the supply line is longer, and transformer's power is larger; it will impact the surrounding electrical appliances also. If changing taps in quick succession, it will lead to the thyristor and its series resistor or transformer burned out. From equation (3) and the equivalent circuit diagram we can see that the smaller the resistance values of R1 and the greater the circular current it caused, when the value becomes as close as zero, the huge circular current can easily burn out switching devices instantaneously.

\section{Researches we have done on HID lamp's energy saving}

The ideal thyristor OLTC technology is the one without transition resistance or reactor components as current limiting element. It regulates the output voltage by the instant change thyristor devices connected to different transformer tap.

When the core technology is good enough, it will be possible to regulate the voltage shift without interruption of output current, no current impact, and no over-voltage or voltage drop phenomenon. Because there is no current limiting resistors or reactors in electrical main circuit, the regulator shows the best performance and its' manufacturing cost is low. However, as the change in voltage and current is difficult to predict, it is rather difficult to make this ideal program into highly-performed and highly reliable products. There are still some university professors conducting related researches.

We have made breakthrough progress in this area, have accessed to a number of national patents and have gotten the support by the Innovation Fund For Technology Based Firms. Products have been developed and put into use in road lighting. They also have played a positive role in lighting energy, increasing lamp life and reducing lighting maintenance workload. 
Products are developed with intelligent monitoring software and have undergoing long-periods of harsh tests in a variety of loads (including no-load, high pressure sodium lamp load, high-pressure mercury lamp, metal halide, mixed lighting load, resistive load) with the cumulative frequency shift over 200,000,000 times. Following is its brief.

\section{A. Autotransformer triac voltage regulation}

Fig. 3 is the schematic diagram of the Main electrical Loop of Autotransformer triac voltage regulation. Only 4 two-ways triac switches are used, the transition resistance is not needed any more by non-contact switch.

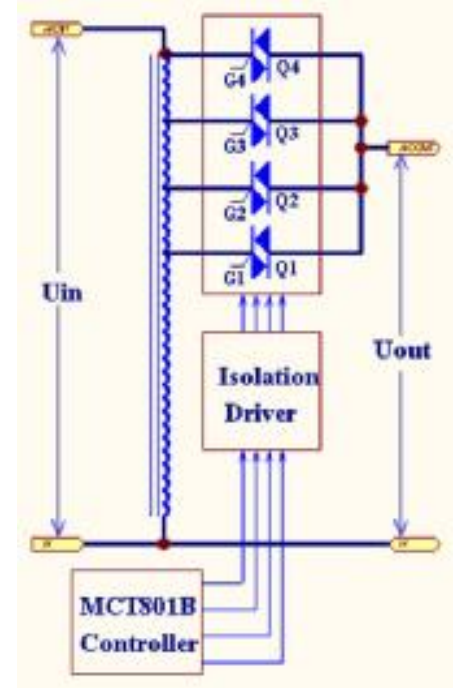

Fig. 3. The main circuit of autotransformer triac voltage regulation

\section{B. The regulated voltage supply regulated by the combination of two transformers}

Fig. 4 is the schematic diagram of the Main electrical Loop of voltage regulation of the combination of two transformers ${ }^{[14]}$, there are totally 15 taps which can be adjusted, the transition resistance is not needed by non-contact switch. It has the Higher precision.

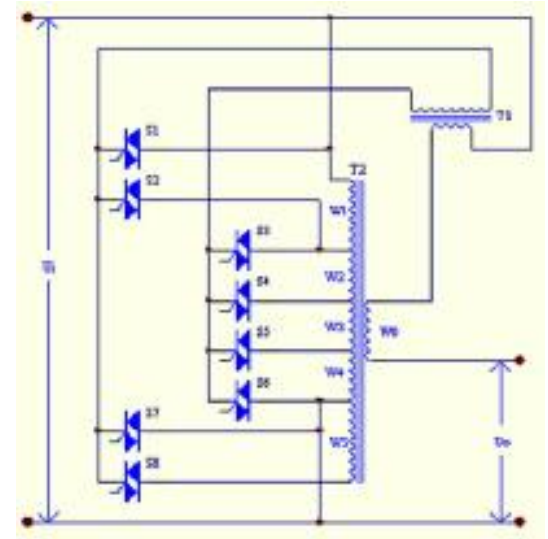

Fig. 4. The main circuit of double voltage regulating transformer combination

The regulated voltage supply is equipped with quite complete monitoring software functions. For the same product, just a few mouse clicks, it can freely switch among "all taps rapid cycling test - fixed regulator - regulation according to energy-saving curve - automatic delay energy-saving ".When it is used as energy-efficient lighting, its voltage accuracy is better than $\pm 1 \%$, and its' saving proportion is over $20 \%$. It can actually prolong the lamp's life and reduce lighting maintenance rate. 


\section{Non-contact OLTC waveforms}

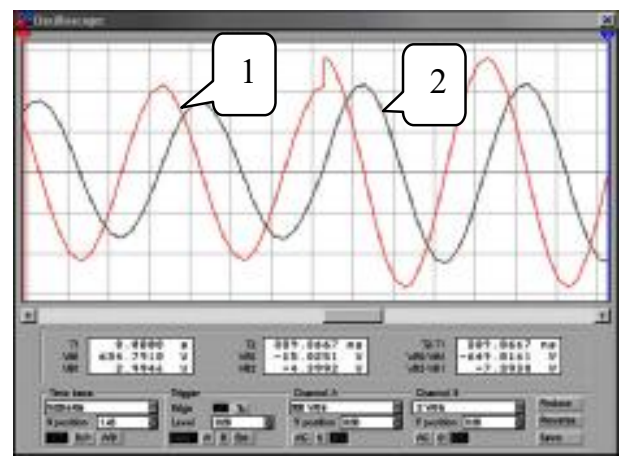

Fig. 5. The simulation of voltage and current waveforms when the inductive load voltage regulation switches

Fig. 5 shows the simulation of voltage and current waveforms of computer when the inductive load voltage regulation switches, the red curve 1 is the voltage waveform, the black curve 2 is the current waveform. Fig. 6 shows the output voltage and output current waveform of high-pressure sodium lamp load regulator, which is shot by an oscillograph on the spot. the yellow waveform 1 is the output voltage waveform; the blue waveform 2 is the output current waveform. Seen from the Fig. the load is an inductive nonlinear load, during the period of switching the output current is continuous and non-impact, there is no output over-voltage or voltage dropping phenomenon.

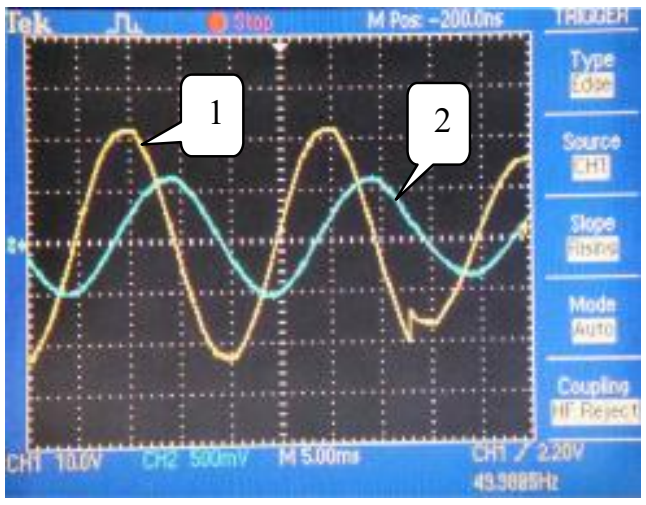

Fig. 6. The output voltage and output current waveform when high-pressure sodium lamp load regulator switches

\section{Conclusion}

High-performance and high reliable non-contact OLTC needs no series resistance or inductance current limiting element in its' main electrical circuit. When changing the transformer taps the current is continuous and non-impact. Besides, it has no over-voltage or voltage drop phenomenon. So the advantages are obvious. Compared with existing technologies, in the same capacity and voltage regulation accuracy, the innovative technology not only has greatly improved the product performance and reliability, but also halves the number of high-power thyristors and makes it no longer need to use high-power current-limiting resistor or reactor. For non-contact OLTC, HID lamps is a rather severe load; in this regard we have accumulated some successful experience. In the next step we are ready to deeper into the research about high voltage system, trying to make a greater contribution to the construction of smart grid.

\section{Acknowledgment}

The work is supported by Nanjing Communications Institute of Technology high level talent research start-up funding project, Jiangsu, China(440105001). 


\section{References}

[1] Shu-wei Huang, Wen-cai Li, Gang Sun. Research and Design of Intelligent Energy-saving Control Device for Street Light. Journal of Hebei Engineering and Technical College In Chinese. $2015.6: 32-35$

[2] D.Rogers, T.Green, Method and apparatus for performing on-load mechanical switching operations,UK patent 0916190.2, September 2009.

[3] Y.L. Zhao, S.T.Dong and X.G. Yang, Study on Non Contract Automatic On-Load Voltage Regulating Distributing Transformer Based on Solid Relay, in Conference Proceedings IEEE IPEMC2006, Shanghai China, vol.1,pp484-488.

[4] X.M.Li, W.Q.Wang,S.C.Zhang, et al. Arcless and Fast Response OLTC Model and its Simulation, High Voltage Engineering In Chinese, vol.2,pp:24-26,2006.

[5] Y.H. Chung, G.H. Kwon, T.B. Park, et al. Dynamic voltage regulator with solid state switched tap changer. Quality and Security of Electric Power Delivery Systems,2003. CIGRE/PES 2003,GRE/IEEE PES InternationalSymposium, pp:105-108, Oct.2003.

[6] Faiz,J., Siahkolah,B . New solid-state onload tap-changers topology for distribution transformers. IEEE Transactions on Power Delivery,no.1,pp:136-141.2003.

[7] K.Abbaszadeh, M.Ardebili, A.R.Alael. Design and Built of on-Load Fully Electronic Tap-Changer with Triac Switch:Simulation and Practical Results,IEEE 1st Power Electronic Driver Systerms Tech Conference,2010,pp.330-334.

[8] Y.X.Yu, C.S.Wang. Theories and Methods on Stability of Power Systems, Beijing: Science Press, 1999.

[9] S.X.Zhou, L.Z.Zhu, X.J.Guo,et al.Power System Voltage Stability and Control,Beijing:China Electric Power Press, 2004.

[10] Guang-liang Wang, A survey on effect of on-load tap changer on the voltage stability, Relay In Chinese, 2008.11:79-84.

[11]Huang Hui, Du Bo. Research and Application of Contactless Load Automatic Voltage Regulating Distribution Transformer. China Electric Power(Technology Edition) In Chinese. 2016 .1:53-55

[12]Jinlong Tu, Kai Hu. The Simulation and Practice of High-performance Non-contact Stabilized Voltage Power Supply. 2015 2nd International Conference on Information Science and Control Engineering. Shanghai,2015,4: 996-1000.

[13]B.Cai, X.S.Cui, X.Chen, Research of Non-Impact Current in Transient Process of Contactless On-Load Voltage Regulation, Electrotechnics Electric In Chinese, pp.1-4, Jan.2010.

[14]Y.Q.Weng, J.L.Tu, Application of the Contactless Electromagnetic Voltage Regulation Technology of in Energy-Saving Lighting, Power Supply Technologies and Applications In Chinese, pp.34-37, Jan.2011. 